\title{
O ALUNO VIRTUAL: UMA OFICINA COMO EXPERIÊNCIA DE APRENDIZAGEM SEMI-PRESENCIAL
}

Eunice Maria Mussoi, PMSM, doutoranda do PGIE, emmussoi@yahoo.com.br Maria Lucia Pozzatti Flores, Ulbra-SM, doutoranda do PGIE, mlflores@ terra.com.br Prof $^{a}$. Dr ${ }^{a}$. Patricia Alejandra Behar, PGIE-PPGEdu/UFRGS, pbehar@ terra.com.br

\section{RESUMO}

Este artigo relata a experiência que as autoras tiveram no planejamento e na aplicação da oficina "O Aluno Virtual". A oficina foi planejada baseada em teorias de vários pesquisadores na área da aprendizagem on-line, desenvolvida através de aulas presenciais e à distância. Os trabalhos resultantes desta oficina foram à construção colaborativa de um formulário sobre o perfil do aluno virtual e artigos sobre este tema, desenvolvidos por pequenas equipes e apresentados resumidamente na seção 3. Essa experiência contribuiu, também, para confirmar que o professor e o tutor devem desenvolver estratégias para melhor conhecer o seu aluno e promover a participação ativa dele no processo de aprendizagem.

Palavras-chave: Aluno Virtual. Aprendizagem On-line. E-Learning.

\section{THE VIRTUAL STUDENT: A WORKSHOP AS A LEARNING EXPERIENCE SEMI-PRESENCE}

\begin{abstract}
This article reports the experience that the authors had in the planning and implementation of the workshop "The Virtual Student." This workshop is designed based on theories of various researchers in the field of online learning, developed through face classes and distance The work resulting from this workshop were to build a collaborative form on the profile of the virtual student and articles on this subject, developed by small teams and summarized in section 3 . This experience helped, too, to confirm that the teacher and tutor must develop strategies to best meet your student and encourage his active participation in the learning process.
\end{abstract}

Keywords: Virtual student. Online learning. E-Learning.

\section{INTRODUÇÃO}

$\mathrm{Na}$ sociedade atual os alunos convivem com as tecnologias digitais, usando o MSN, o e-mail, entre outros, para fazerem contatos com outras pessoas. Basta um indivíduo ter acesso a um computador ligado à Internet que ele está conectado ao mundo, podendo explorá-lo inclusive para o estudo. Mas apesar dos alunos terem toda essa tecnologia a sua disposição, não significa que ele tenha garantia de sucesso em um curso à distância. Para ele ter sucesso é preciso que ele aprenda a aprender à distância.

Pensando no tema de como trabalhar o aluno virtual, para que realmente ele tenha uma aprendizagem on-line, foi desenvolvida em uma disciplina do programa de Pós Graduação em Informática na Educação da UFRGS, a oficina "O Aluno virtual", em 1/2007 e, após, aplicado em 1/2008. A aplicação prática da oficina visou à validação do material que foi planejado e desenvolvido na própria oficina, bem como, reconstruílo de acordo com as necessidades do público. Esta oficina foi disponibilizada no endereço http://homer.nuted.edu.ufrgs.br/oficinas_2008/. A experiência da construção e aplicação desta oficina é o objeto do relato neste artigo. Na próxima seção será abordada a estrutura da oficina, seus objetivos, ferramentas, metodologia e avaliação. 
Na seção 3, procede-se a uma breve apresentação dos resultados da oficina e, por fim, a seção 4 apresenta as considerações finais.

\section{A OFICINA “O ALUNO VIRTUAL"}

A oficina teve por objetivo proporcionar ao educador uma formação que potencialize a aprendizagem online focada no aluno virtual. Para alcançar esse objetivo as oficineiras produziram um material educacional digital - "material educacional digital é todo material didático elaborado com objetivos relacionados à aprendizagem e que incorpora recursos digitais" (Behar \& cols, 2008, p.33), composto de texto básico, elaborado a partir da literatura pesquisada e o validaram através de desafios propostos durante a oficina. Os desafios principais foram: criar um formulário sobre o perfil do aluno virtual e um artigo coletivo sobre este tema.

A oficina consta de um referencial teórico, tendo como objetivo o conhecimento pela comunidade (professor/alunos) das estratégias e ferramentas pedagógicas, que proporcionam o desenvolvimento de uma aprendizagem on-line focada no aluno. Ela foi desenvolvida na modalidade semi-presencial, com a realização de desafios, tendo como público alvo os alunos da graduação e pós-graduação. O mapeamento geral do projeto da oficina, englobando conteúdo e ferramentas, encontra-se na Figura 1.

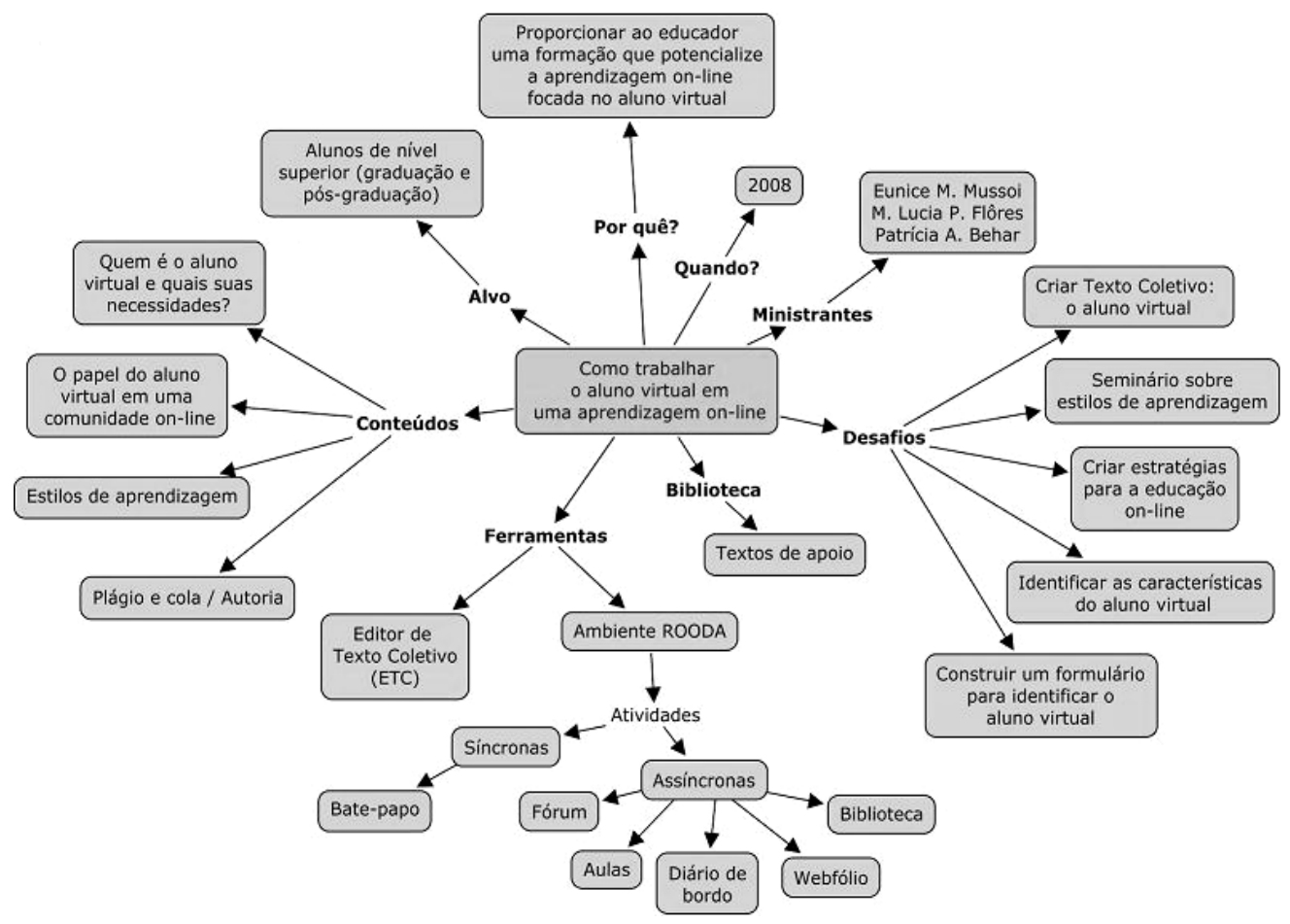

Figura 1 - Mapa Conceitual da Oficina

O referencial teórico é um texto específico para trabalhar as aulas com os alunos virtuais, englobando idéias de vários autores da área, citados na bibliografia consultada, principalmente Palloff e Pratt (2004). Este texto serviu como leitura e referência básica para as discussões, que a partir delas os alunos complementaram com suas idéias, vivências e outros autores.

Entre os objetivos da oficina estava abordar e discutir questões referentes ao aluno virtual, como: definir o perfil deste público em EAD; ser um docente focado no aluno; os conflitos; o plágio e a cola. Criar texto colaborativo que contemple os conteúdos propostos para a oficina, através do Editor de Texto Coletivo (ETC) 
(http://homer.nuted.edu.ufrgs.br/etc/). Criar um formulário do Perfil do Aluno Virtual. Orientar os alunos do curso na compreensão e utilização dos conhecimentos adquiridos, em sua prática pedagógica. Promover a participação ativa do aluno no seu processo da aprendizagem, através de atividades que provoquem desequilíbrios e re-equilíbrios sucessivos. Familiarizar os alunos com o uso das ferramentas do ambiente virtual ROODA (https://www.ead.ufrgs.br/rooda/index.php), tais como: fórum de debates, diário de bordo, sala de bate-papo, e-mail, biblioteca, etc. No site da oficina foi disponibilizada uma biblioteca com glossário e um resumo do projeto.

A metodologia do curso foi composta por momentos presenciais e a distância, onde em cada aula presencial, o assunto foi apresentado pelo professor, que destacou conceitos para ajudar o participante na interpretação do material, promoveu discussões e indicou as atividades e fontes de pesquisa para o mesmo. As aulas à distância foram discutidas e suas ações foram combinadas com antecedência, no momento presencial que a antecedeu.

É importante poder aproveitar a riqueza de experiências, conhecimentos e interpretações que os alunos trazem consigo, por isso, os alunos da oficina foram estimulados a interagirem e lerem os comentários dos colegas, e também, a fazerem as suas contribuições em um intercâmbio horizontal. Os encontros da oficina foram divididos em quatro momentos, sendo os dois primeiros presenciais, o terceiro on-line e o quarto novamente presencial para a conclusão dos trabalhos.

A interação, presencial e a distância, foi muito incentivada no decorrer do curso, pois as oficineiras acreditam que são as relações entre os objetivos da aprendizagem e as vivências dos alunos, que os levam a refletir e questionar, possibilitando o desenvolvimento da capacidade de criar e de adaptar a aprendizagem adquirida a cada situação profissional. Essas interações foram possíveis com as ferramentas do Rooda. A cada semana foram apresentadas as leituras obrigatórias, complementares e links de interesse, para que os alunos realizassem as suas atividades. Ainda, foi constantemente incentivada à contribuição de todos. Essas contribuições foram notadas em atividades que envolviam:

-Explorar a ferramenta do Editor de Texto Colaborativo (ETC), trabalhando com um texto colaborativo do grupo, sobre o aluno virtual.

-Colocar o texto coletivo e demais atividades coletivas, no webfólio do grupo.

-Registrar as impressões de cada aula no Diário de Bordo.

-Participar do Fórum da semana.

-Participar do Chat.

-Criar um formulário que identifique o perfil do aluno virtual, com base na sua vivência e nas características do aluno virtual estudadas nos textos.

-Apresentar os trabalhos dos grupos, incluindo o texto coletivo e o formulário: perfil do aluno virtual.

As oficineiras re-escreveram o formulário sobre o perfil do aluno virtual, constando às sugestões dadas por elas próprias e por todos os participantes de cada grupo de trabalho, o qual foi colocado nos resultados.

Nesta oficina, a avaliação foi considerada como um processo contínuo e se deu no decorrer das atividades propostas. Foram considerados alguns critérios, como: participação no fórum, atividades realizadas, participação em aula e diário de bordo. Para ter um bom rendimento e com base na obra de Palloff e Pratt (2004), foi considerado que os alunos virtuais deveriam desenvolver as seguintes atitudes:

-Acessar regularmente ao ambiente virtual, no mínimo duas vezes na semana. -Ler e estudar os materiais indicados pelos professores e/ou pela página do curso. -Ler as mensagens dos professores e dos demais colegas de curso.

-Contribuir com seus comentários sobre os materiais de estudo e as mensagens dos colegas e/ou formadores. 
-Desenvolver a autonomia, a cooperação e a interação.

-Vivenciar um processo de aprendizagem em comunidade.

-Cumprir com as atividades propostas.

-Refletir sobre o processo de aprendizagem individual e em grupo.

-Contribuir com outras fontes de conhecimento.

-Planejar e desenvolver ações.

A estrutura de toda a oficina, o número de encontros, a modalidade semipresencial, bem como, os critérios de avaliação foram apresentados e discutidos no primeiro encontro. A oficina atendeu a aproximadamente quinze alunos e os resultados alcançados serão apresentados na seção que segue.

\section{RESULTADOS}

Nesta oficina foram alcançados os objetivos propostos no projeto, isto é, foi possível conhecer algumas estratégias e ferramentas pedagógicas, que proporcionam o desenvolvimento de uma aprendizagem on-line focada no aluno. Usando o editor de texto ETC, cada grupo construiu coletivamente um artigo sobre esse tema, cujos resumos estão na subseção 3.2. Através de um processo interativo foi desenvolvido um formulário para traçar previamente um perfil do aluno virtual e assim adequar o planejamento das aulas e do trabalho do professor com esse aluno. Os formulários criados pelos alunos foram sintetizados em um único documento, sem alterar a proposta inicial das autoras e dos alunos. O resultado é o formulário (subseção 3.1) que segue.

\section{1-Formulário - PERFIL DO ALUNO VIRTUAL}

\section{I - DADOS PESSOAIS}

1-Nome:

Nick:

2-Endereço para contato:

Rua:

$\mathrm{N}^{\mathrm{o}}$ :

CEP:

Bairro:

Cidade:

UF: País:

Telefone(s): (....)

Celular: (....).

E-mail/MSN:

Homepage:

3-Sexo: ( ) Feminino ( )Masculino

4-Idade: ( )de 15 a 20 ( ) de 21 a 30 ( ) de 31 a 35 ( ) de 36 a 40

( ) de 41 a 45 ( ) de 46 a 50 ( ) de 51 a 55 ( ) de 56 a 60

( ) de 61 a 65 ( ) de 66 a 70 ( )outro. Qual?....

5-Estado Civil: ( ) solteiro ( )casado ( )viúvo ( )separado

( )divorciado ( )outro.

6-Tem filhos? ( )sim ( )não Quantos?

Idades?

7-Possui algum tipo de necessidade especial? ( ) sim （ )não

Qual? 
8-Escolaridade: ( )Fundamental ( )Médio ( )Universitário ( )Pós-graduação ( )outro. Qual?

9-Qual a profissão?

10-Carga horária de trabalho semanal?.

\section{II - DADOS TÉCNICOS}

1-Você disponibiliza de Hardware: (Escolha múltipla)

( ) $\mathrm{PC}$

( ) Notebook

( ) Impressora

( ) Scanner

( ) Webcan

( ) Microfone

( ) Multimídia

2-Sistema Operacional/ software utilizados: (Escolha simples ou múltipla)

( ) Windows

( ) Linux

( ) Windows/Linux

( ) Adobe Acrobat

( ) MSN

( ) Outros. Quais?

3- Tipo de conexão utilizada: (Escolha simples ou múltipla)

( ) Banda larga. Velocidade?

( ) Discada.

( ) Outra. Qual?

4- Você já utilizou as plataformas: (Escolha simples ou múltipla)

( ) ROODA

( ) MOODLE

( ) TELEDUC

( ) E-PROINFO

( ) Outros. Quais?

\section{III - SOBRE O CURSO EM EAD}

1- Para a realização do curso em EAD, você acessa a Internet (múltipla escolha):
a) De casa
b) Da escola
c) Do trabalho
d) Do cybercafé
e) Outros. Quais?

2- Qual o tempo semanal disponível para a realização deste curso?

a) Até 5 horas

b) De 5 a 10 horas

c) De 11 a 15 horas 


\section{d) De 15 a 20 horas}

3- Por que escolheu fazer um curso em EAD? (Escolha simples ou múltipla)

a) Flexibilidade de horário

b) Autonomia

c) Possibilidade de crescimento profissional

d) Uso de novas tecnologias

e) Outros. Quais?

4- Qual a sua preferência em relação aos materiais disponibilizados para estudo, no curso em EAD? (Escolha simples ou múltipla)

( ) áudio ( ) vídeo ( ) texto ( ) Outros. Quais?

5-Minha necessidade de fazer esse curso é: (escolha simples) ( )Alta - Preciso do curso imediatamente para um objetivo específico.

( ) Moderada - Poderia fazer o curso no campus mais tarde ou fazer outro curso.

( ) Baixa - Posso adiá-lo.

6-Sentir que faço parte de um grupo: (escolha simples)

( )Não é necessário para mim.

( )É razoavelmente importante para mim.

( )Muito importante para mim.

7-Sobre minha capacidade de trabalhar com a tecnologia: (escolha simples)

( ) Sei lidar muito bem com o computador.

( )Conheço alguma de computador e de Internet.

( )Não tenho familiaridade com computador e não me sinto à vontade em navegar na rede.

\section{IV - SOBRE A APRENDIZAGEM}

1-Como você se considera: (múltipla escolha)

( )tem bom humor.

( )é flexível e aberto para novidades.

( )é comprometido com a comunidade.

( )é honesto em seu(s) trabalho(s)

2-Eu me classificaria como uma pessoa que: (escolha simples)

( )Frequentemente termina as atividades antes do prazo.

( )Precisa ser lembrada para terminar as atividades no prazo.

( ) Transfere as atividades até a última hora ou não às termina.

3-O debate em sala de aula é: (escolha simples)

( )Raramente útil para mim.

( )Às vezes útil para mim.

( )Quase sempre útil para mim.

4-Quando o professor passa as instruções para um trabalho, eu prefiro: (escolha simples)

( )Descobrir sozinho o que as instruções dizem.

( ) Tentar seguir as instruções e depois pedir ajuda, quando necessário.

( ) Que alguém explique o que fazer. 
5-Preciso que os professores comentem as atividades postadas: (escolha simples)

( )Em poucas semanas, para que eu possa revisar o que escrevi.

( )Em poucos dias, ou então esqueço o que fiz.

( )Imediatamente, ou então fico muito frustrado.

6-Como leitor, eu me classifico como: (escolha simples)

( )Bom - em geral entendo o texto sem ajuda.

( )Médio - às vezes preciso de ajuda para compreender o texto.

( )Inferior à média.

7-Quando preciso de ajuda para entender o assunto: (escolha simples)

( ) Sinto-me à vontade em pedir esclarecimento ao professor.

( )Não me sinto à vontade em pedir esclarecimento ao professor, mas o faço.

( )Nunca peço ajuda ao professor, para não ter de admitir que não entendesse algo.

8-Costuma trabalhar (elaborar texto, montar curso, preparar aula,...) juntamente com outra(s) pessoa(s)?

( ) $\operatorname{Sim}$ ( )Não

Como?

\subsection{Produção de texto dos alunos}

Os grupos produziram textos coletivos, que se transformaram em artigo científico, com o tema relacionado ao aluno virtual. Utilizaram o Editor de Texto Coletivo (ETC), que é um editor que permite a interação entre sujeito e objeto, permitindo trocas de idéias entre os autores do texto, sem deixar de respeitar o tempo, a individualidade e os processos de cada um. O resumo de cada artigo está a seguir, nas subseções 3.2.1, 3.2.2, 3.2.3.e 3.2.4.

\subsubsection{Aluno virtual: necessidades e possibilidades}

Para o aluno virtual poder acompanhar a aprendizagem são necessárias algumas exigências, como equipamentos adequados e experiência mínima em informática. Ser um aluno virtual possui vantagens, como maior liberdade de escolha de como e de que forma estudar. O aluno virtual necessita de alguns fatores que auxiliem na busca de sua autonomia, entre elas está o feedback. As mensagens de feedback devem ser substanciais e claras. Para melhorar a autonomia do aluno virtual, o professor deve saber que a educação a distância não é transmissão de conhecimento, mas sim um processo de motivação e de cumplicidade com o aluno. Todas estas mudanças fazem com que o aluno seja um sujeito agente de sua aprendizagem.

\subsubsection{A anamnese do aluno virtual}

Este artigo aborda questões sobre a anamnese, o aluno virtual e comunidades virtuais de aprendizagem. Apresentando como instrumento de análise a ser utilizado pelo professor de educação à distância, como uma forma de conhecer e delinear o perfil de cada integrante da comunidade virtual de aprendizagem, uma entrevista virtual exploratória situacional. 


\subsubsection{Texto Coletivo: Estilos de Aprendizagem}

Este artigo aborda os estilos de aprendizagem dos alunos virtuais. Estes diferentes estilos são preocupações comum e constante entre professores, devido às diferenças entre as pessoas que compõem a sala de aula virtual. Esse assunto gera muita discussão entre os professores sobre a necessidade de adaptar e de apresentar um material pedagógico que satisfaça os diferentes estilos e preferências de aprendizagem. O professor, ao planejar suas aulas deve diversificar suas atividades para contemplar o maior número de estilos de aprendizagem possível. Entretanto, as atividades colaborativas, sejam elas por trabalhos realizados em pequenos grupos, simulações, ou outros métodos, são as melhores maneiras de atender aos diversos estilos de aprendizagem dos alunos. Ao compartilhar as idéias e o trabalho, essas atividades podem levar a criação de novos conceitos e significados a respeito dos conceitos estudados proporcionando o desenvolvimento da criatividade e da autonomia.

\subsubsection{Oficinas virtuais de aprendizagem: $\mathrm{o}$ aluno virtual}

O presente ensaio tem por objetivo evidenciar o uso de novas tecnologias digitais em meio aos ambientes virtuais de aprendizagem (AVA), analisando o espaço que o aluno virtual ocupa em meio a isso. O artigo foi de natureza empírica qualitativa, tendo como suporte a metodologia da construção de texto coletivo, através da plataforma ETC. Os resultados obtidos mostraram a emergência de introduzir disciplinas curriculares além de discussões acerca do espaço que o aluno virtual tem tido. Assim, as tecnologias digitais e os alunos virtuais precisam ser entendidos como integrantes de um novo processo de aprendizagem à distância.

\section{CONSIDERAÇÕES FINAIS}

A atuação das autoras como professoras e tutoras nesta oficina trouxeram, também, a experiência de "aulas virtuais" confirmando que, além da preocupação com a aprendizagem, o professor deve primar pela motivação do aluno; pela intensa interação aluno/professor; aluno/tutor e aluno/aluno; pela escolha de materiais e ferramentas virtuais que contemplem alguns dos estilos de aprendizagem, no ambiente virtual.

O professor e o tutor devem desenvolver estratégias para melhor conhecer o seu aluno, suas limitações e possibilidades, para planejar e promover a participação ativa dele no processo da aprendizagem, através de atividades interativas que provoquem desequilíbrios e re-equilíbrios sucessivos, com o uso de tecnologias que estejam ao real alcance do aluno. $\mathrm{O}$ formulário proposto neste artigo, quando aplicado antes de iniciar o curso e de construir os conteúdos, contribui com o conhecimento prévio do perfil dos alunos. Desta forma, pode ser possível construir e adaptar conteúdos e atividades que visem corresponder às expectativas dos alunos.

$\mathrm{O}$ aluno em uma aprendizagem on-line necessita de orientações que o ajudem a aprender, a reconhecer o que lhe favorece a aprendizagem em uma sala de aula virtual, conhecer quais são as ferramentas, como utilizá-las, onde buscar materiais, como superar suas limitações, etc. O feedback dado ao aluno deve ser imediato e seu texto relevante.

A dinâmica desta oficina e os materiais produzidos serviram, em parte, para confirmar o que alguns dos teóricos escolhidos já apontavam, em relação ao aluno virtual e a aprendizagem on-line. Principalmente, a vivência desta oficina serviu como base de um processo de crescimento, no qual as oficineiras, enquanto alunas, tiveram a oportunidade de tomar as rédeas de sua aprendizagem, sair em busca das condições que as ajudaram construírem e testar seu conhecimento e seu auto-conhecimento. 


\section{REFERÊNCIAS BIBLIOGRÁFICAS}

-BEHAR, P. A. (orgs.). Modelos pedagógicos em educação à distância. Porto Alegre: Artmed, 2009.

-PALLOF, R; PRATT, K. O aluno virtual: um guia para trabalhar com estudantes online. Tradução de Vinícius Figueira. Porto alegre: Artmed, 2004.

\section{BIBLIOGRAFIAS CONSULTADAS PARA O PROJETO}

-BELLONI, M. L. Educação a Distância. Campinas, SP: Associados, 1999.

-Ambientes virtuais de aprendizagem: do "ensino na rede à aprendizagem em rede", disponível em: <http://www.tvebrasil.com.br/salto/boletins2005/nfa/tetxt2.htm>.

Acesso em: 27 de maio de 2007.

-CHAVES, E. O. C. A escola que queremos: o papel da tecnologia. Disponível em: $<$ http://www.escola2000.org.br/pesqu. pps>. Acesso em: 12 de maio de 2007.

-MANTOVANI, A. M. - Interação, colaboração e cooperação em ambiente de aprendizagem computacional. Disponível em:

<http://www.labin.lasalle.tche.br/infoedu/>. Acesso em: 30 de maio de 2007.

-NEVADO, R. A. Ambientes virtuais que potencializam as relações de ensinoaprendizagem. Disponível em:

$<$ http://www.tvebrasil.com.br/salto/boletins2005/nfa/tetxt2.htm>. Acesso em: 12 de maio de 2007.

-PALLOF, R; PRATT, K. O aluno virtual: um guia para trabalhar com estudantes online. Tradução de Vinícius Figueira. Porto alegre: Artmed, 2004.

-PRIMO, A. Enfoques e desfoques no estudo da interação mediada por computador. Disponível em:

$<$ http://www6.ufrgs.br/limc/PDFs/enfoques_desfoques.pdf $>$. Acesso em: 12 de maio de 2007.

-PRIMO, A. Quão interativo é o hipertexto? Da interface potencial à escrita coletiva. Disponível em: <http://www6.ufrgs.br/limc/PDFs/quao_interativo_hipertexto.pdf >.

Acesso em: 12 de junho de 2007.

-PRIMO, A. Conflito e cooperação em interações mediadas

por computador. Disponível em: <http://www6.ufrgs.br/limc/PDFs/conflito.pdf>.

Acesso em: 12 de junho de 2007.

-RECUERO, R. C. Comunidade Virtual uma abordagem teórica. Disponível em:

$<$ http://www.pontomidia.com.br/raquel/teorica.htm>. Acesso em: 10 de junho de 2007.

-SAMPAIO-RALHA, J. Comunidades Virtuais: Definição, origens e aplicações.

Disponível em: <w?down=79>. Acesso em: 30 de maio de 2007.

-SAMPAIO-RALHA, J. O Animador de Comunidades Virtuais. Disponível em:

$<$ http://www.escola2000.org.br/pesquise/texto/textos_art.aspx/id=70>. Acesso em: 30 de maio de 2007.

-SANTAROSA, L. C.; NITZKE, J. A.; CARNEIRO, M. L. F.; GELLER, M. Criação

de ambientes de aprendizagem colaborativa. Disponível em:

$<$ http://penta.ufrgs.br/pgie/sbie99/acac.html>. Acesso em: 12 de maio de 2007.

-SARTORI, A. S.; ROESLER, J. Comunidades virtuais de aprendizagem: espaços

de desenvolvimento de sociabilidades, comunicação e cultura. Disponível em:

$<$ http://www.pucsp.br/tead/n1a/artigos\%20pdf/artigo1.pdf $>$. Acesso em: 11 de junho de 2007.

-SCHLEMMER, E. Projetos de aprendizagem baseados em problemas: Uma metodologia interacionista/construtivista para formação de comunidades em Ambientes Virtuais de Aprendizagem. Disponível em:

$<$ http://www.ricesu.com.br/colabora/n2/artigos/n_2/id02.htm>. Acesso em: 23 de maio de 2007. 
-TOLEDO, F. S. Pedagogia on-line. Disponível em:

$<$ http://www.lo.unisal.br/nova/ead/artigo2.html>. Acesso em: 11de junho de 2007. -TIJIBOY, A. V.; MAÇADA, D. L. Cooperação/Colaboração em Ambientes

Telemáticos. Disponível em:

$<$ http://www.aprodados.com.br/downloads/textospedagogicos/aprendizagemcooperativa.pdf>. Acesso em: 10 de junho de 2007. 